\title{
Possibilities of Controlling the Dynamic Properties of a Cylindrical Piezoceramic Acousto- electronic Device with Two-frequency Resonance Excitation
}

\author{
O. Leiko, N. Bogdanova, O. Bogdanov, O. Drozdenko, K. Drozdenko
}

\author{
National Technical University of Ukraine "Igor Sikorsky Kyiv Polytechnic Institute», \\ 16, Politekhnichna St., 03056 Kyiv, Ukraine
}

(Received 21 July 2020; revised manuscript received 18 December 2020; published online 25 December 2020)

\begin{abstract}
It is shown that in the dynamic properties of acoustoelectronic devices in the form of a coaxial system including two cylindrical piezoceramic shells with electric excitation of each shell at its resonant frequency, two groups of related properties can be distinguished. The first of them - potentially possible properties is determined by these devices design characteristics such as electrophysical parameters of the shells piezoceramics, diameters, thicknesses and resonance frequencies of shells, physical parameters of their filling media. The second group - operatively controlled properties - is formed by their dynamic properties operatively controlled from the electrical side of the devices. By the method of numerical analysis with specific reference on acoustic fields, the regularities of the behavior of potentially possible dynamic properties of such devices for variants of their designs, when the inner shell resonance frequency is less, close or more than the outer shell resonance frequency were established. The quantitative influence of operational dynamic control methods from the electric side of the devices on them was obtained. The physical interpretation of the described dynamic properties causes was given.
\end{abstract}

Keywords: Acoustoelectronic device, Two-frequency resonance excitation, Dynamic properties, Potentially possible, Operatively controlled.

DOI: 10.21272/jnep.12(6).06003

PACS number: $43.38 .+\mathrm{n}$

\section{INTRODUCTION}

Acoustoelectronic systems with dynamic control of their parameters are becoming increasingly important when creating modern echolocation multifunctional devices [1-3].

The practical implementation of such systems is caused by the fact that they include the acoustoelectronic devices formed from piezoceramic energy transducers [4-11]. These electromechanical devices are characterized by the presence of electrical and mechanical parts, due to which active operational control of their parameters during operation is carried out by electric way.

The insertion of piezoceramic energy-converting elements into the devices has significantly complicated the physical processes occurring in them [12]. Consideration of these processes in the "end-to-end" tasks for the determination of the existing physical fields in such devices has led to the necessity of taking into account new factors - connection of electric, mechanical and acoustic fields during energy transformation, connection of acoustic fields of devices in the system during the process of its acoustic field formation and connection between the processes of energy transformation and its formation in surrounding spaces.

These connections are based on electrical elasticity of piezoceramic transducers and multiple exchanges of radiated and reflected sound waves in systems $[2,3,5$, 8-12] between their elements.

Naturally, the transition to active methods for controlling the transducers parameters in the process of their work required a revision of the approaches to their construction $[2,5]$.

An analysis of the structure of the construction of the acoustoelectronic device (Fig. 1) in one of these approaches suggests that in terms of the influence on the dynamic parameters, the characteristics of this device can be divided into two groups. One group determines the current operational control capabilities of the device parameters, and the second group determines the potential capabilities of such control. The first group includes amplitudes and phases of excitation voltages of piezoceramic shells of the acoustoelectronic device. The second group of characteristics consists of electrophysical compositions of shells piezoceramics; shell diameters and thicknesses; physical parameters of the media filling the shells; resonance frequencies of shells in vacuum. In work [5], the dynamic properties of the output parameters of the device under consideration at identical resonance frequencies of its piezoceramic shells, thicknesses and media filling them were studied. The results of work [3] made it possible to establish abrupt changes in the given type of acoustoelectronic devices potential dynamic properties at the same resonance frequencies of shells and filling media, but different relative thickness of shells.

The purpose of this work is to study the potential possibilities of controlling the dynamic properties of an acoustoelectronic device - a coaxial system of cylindrical piezoceramic shells with a change in the resonance excitation frequencies of piezoelectric shells.

\section{THE PROBLEM STATEMENT. RESULTS OF RESEARCHES}

We define potential possibilities of controlling the dynamic properties of cylindrical piezoceramic acoustoelectronic devices (Fig. 1), in the construction scheme of which the idea of different resonance frequencies in vacuum of each of its piezoceramic shells is implemented. Note that the considered acoustoelectronic device shells resonance frequencies are determined by average radius of shells and electrophysical parameters of piezoceramics compositions, from which these shells [6] are 
formed. At the same time, the conditions of the electrical parameters operational control remain unchanged.

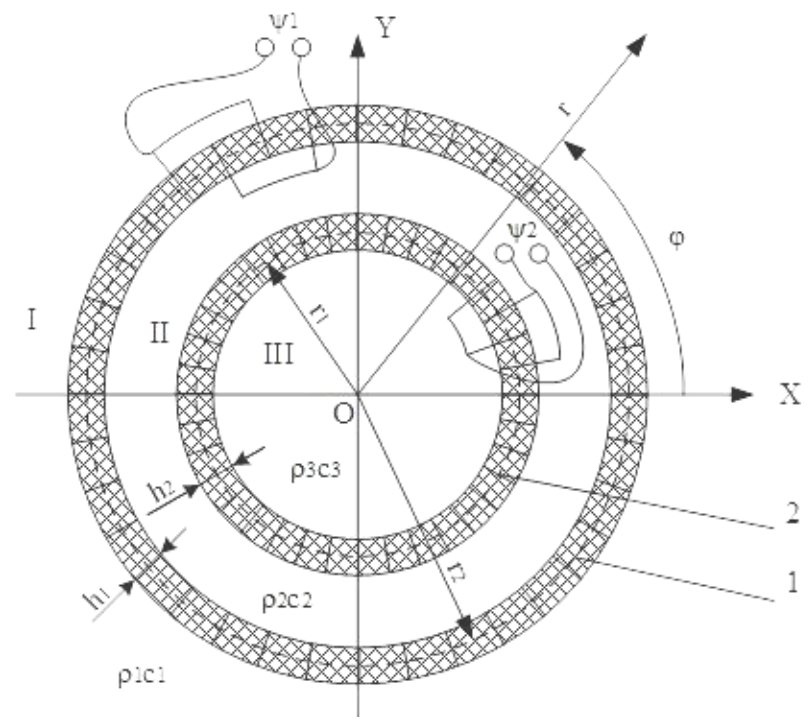

Fig. 1 - Normal section of the dynamically excited acoustoelectronic device

The acoustoelectronic device is formed of two coaxial cylindrical piezoceramic shells 1 and 2 with medium radiuses $r_{1}$ and $r_{2}$ and thicknesses $h_{1}$ and $h_{2}$. Each of the shells has a circumferential polarization, is assembled of $M_{1}$ and $M_{2}$ rigidly glued piezoceramic elements electrically connected in parallel. Harmonic electric voltages are supplied to flat faces of elements of the first and second shells $\psi_{1}=\Psi_{01} e^{-i \omega t}$ and $\psi_{2}=\Psi_{02} e^{-i(\omega t-\varphi)}$, where $\Psi_{01}$ and $\Psi_{02}$ are the voltage amplitudes, $\omega$ is the circular frequency, $\varphi$ is the phase shift between voltages $\psi_{1}$ and $\psi_{2}$. The shells can be made of the same compositions of piezoceramics or from different ones. The device is placed in a medium with density $\rho_{1}$ and speed of sound $c_{1}$, and space between shells and inside the second shell is filled with media with densities $\rho_{2}$ and $\rho_{3}$, speeds of sound $c_{2}$ and $c_{3}$, respectively.

Analytical relations for the determination of all three physical fields - electric, mechanical and acoustic involved in the operation mode of the considered acoustoelectronic device adjusted for all these fields connectivity, were obtained in the work [5]. We use them to quantify the potential possibilities of the device dynamic properties control. We confine our study to estimation of the device acoustic field pressure frequency relationships in the far zone, although similar estimates can be made for other physical fields. As follows from [5], the acoustic pressure of the device is determined by the expression $p_{1}=i \omega \rho_{1} \Phi_{1}\left(k_{1} r\right)=A H_{0}^{(1)}\left(k_{1} r\right)$, where $A=\frac{i \omega \rho_{1} W_{01}}{k_{1} H_{0}^{(1) \prime}\left(k_{1} r_{11}\right)} ; k_{1}$ is the wavenumber of the external medium; $W_{01}$ is the radial component of the vector of distances from the midsurface points of the external shell determined from the system of algebraic equations (8) in work [5]; $H_{0}^{(1)}\left(k_{1} r_{11}\right)$ is the Hankel function of the first kind; $r_{11}=r_{01}+\frac{h_{1}}{2}$ is the external surface of the first shell; the stroke means the derivative of the function by argument $r$. For far field $\left|p_{1 д}\right|=\left|p_{1}\right|$ at large values $k_{1} r$.

Calculations were performed for the following characteristics of the dynamically excited device: the average radiuses of the external $(s=1)$ and internal $(s=2)$ piezoceramic shells were $r_{1}=0.2 \mathrm{~m}$ and $r_{2}=0.18 \mathrm{~m} ; 0.16 \mathrm{~m} ; 0.14 \mathrm{~m} ; 0.12 \mathrm{~m} ; 0.1 \mathrm{~m} ; 0.08 \mathrm{~m} ; 0.06 \mathrm{~m}$; the thicknesses of the shells were equal to $5 \%$ of their average radiuses; the number of prisms forming the shells was assumed to be the same $M_{1}=M_{2}=48$; piezoceramic media of the shells - for the external shell the composition of the BTC system: $\gamma_{1}=5400 \frac{\mathrm{kg}}{\mathrm{m}^{3}} ; d_{33,1}=113 \cdot 10^{-12} \frac{\mathrm{C}}{\mathrm{N}}$; $c_{33,1}^{E}=10.5 \cdot 10^{10} \frac{N}{m^{2}} ; \varepsilon_{33,1}^{S}=10.4 \cdot 10^{-9} \frac{F}{m}$; for the internal shell the composition of the PZT system: $\gamma_{2}=7200 \frac{\mathrm{kg}}{\mathrm{m}^{3}} ; \quad \quad d_{33,2}=320 \cdot 10^{-12} \frac{\mathrm{C}}{\mathrm{N}} ;$ $c_{33,2}^{E}=7.5 \cdot 10^{10} \frac{N}{m^{2}} ; \quad \varepsilon_{33,2}^{S}=19.5 \cdot 10^{-9} \frac{F}{m} ;$ the wave resistances of the media in the first, second and third regions, respectively, were $\rho_{1} c_{1}=\rho_{2} c_{2}=1.5 \cdot 10^{6} \frac{\mathrm{kg}}{\mathrm{m}^{2} \mathrm{~s}}$ and $\rho_{3} c_{3}=0$; the amplitudes of the excitation voltages were equal to $\Psi_{01}=200 \mathrm{~V} ; \quad \Psi_{02}=200 \mathrm{~V} ; 120 \mathrm{~V} ; 0 \mathrm{~V}$; the phase shift between $\psi_{1}$ and $\psi_{2}$ was equal to $\varphi=0 ; \frac{\pi}{2} ; \pi$. The frequency range from 0 to $35 \mathrm{kHz}$ was investigated.

Some of the numerical experiment results are shown in Fig. 2-Fig. 4. They correspond to intrinsic resonance frequencies $f$ of piezoceramic shells in a vacuum: for the external shell $f_{1}=3.5 \mathrm{kHz}$; for the internal shell $f_{2}=2.83 \mathrm{kHz} \quad$ (Fig. 2); $f_{2}=3.64 \mathrm{kHz}$ (Fig. 3); $f_{2}=5.1 \mathrm{kHz}$ (Fig. 4).

The analysis of the obtained results shows the following. First, the operatively controlled dynamic properties of the acoustoelectronic device depend in a complex manner on the amplitudes and phase shift of the excitation voltages of the shells. Secondly, the potential possibilities of controlling the dynamic properties of this device are largely determined by the device design characteristics, such as the average radiuses of its shells and the electrophysical parameters of these shells piezoceramics compositions. These two characteristics determine the intrinsic resonance frequencies of cylindrical piezoceramic shells in vacuum.

The analysis of the dynamic properties potential possibilities of the device under consideration when its design characteristics change (Fig. 2-Fig. 4) allows to identify the following their features. At all intrinsic resonance frequencies of shells, frequency relationships of 

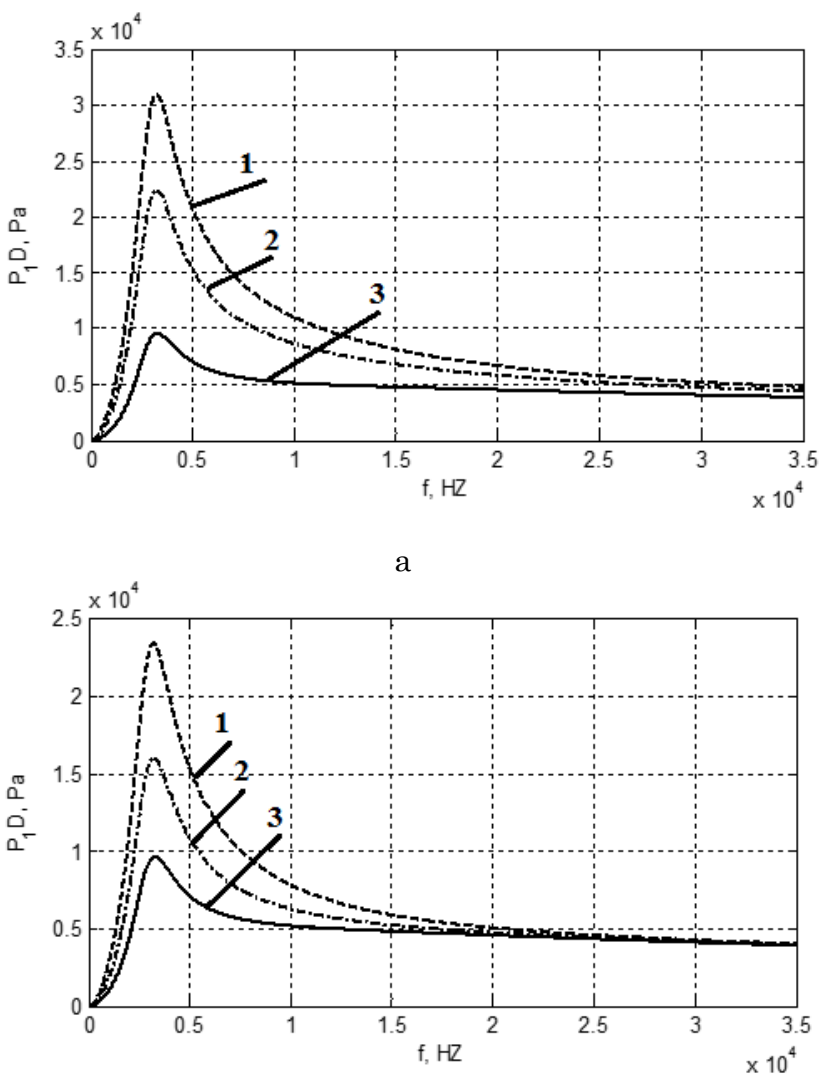

$\mathrm{b}$

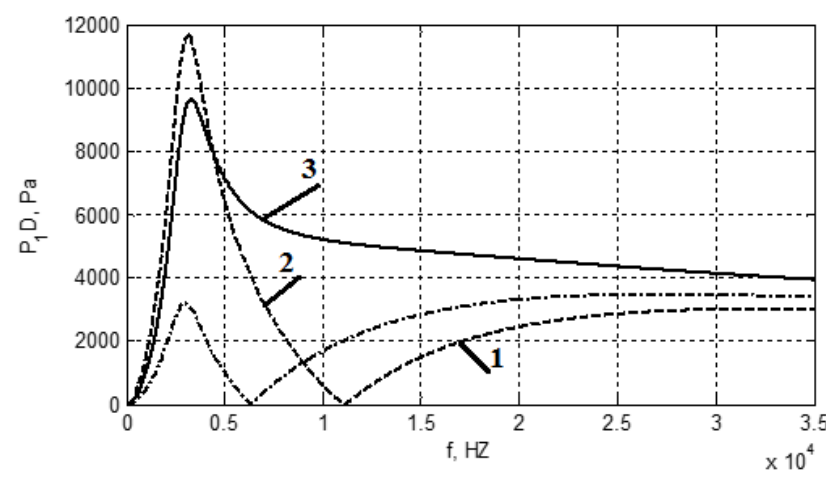

$\mathrm{c}$

Fig. 2 - Frequency dependences of acoustic pressure amplitudes of the dynamically excited acoustoelectronic device at $f_{1}=3.5 \mathrm{kHz} ; f_{2}=2.83 \mathrm{kHz}$;

$\frac{\Psi_{02}}{\Psi_{01}}=1.0(1) ; 0.6(2) ; 0(3) ; \varphi=0(a) ; \frac{\pi}{2}(b) ; \pi(c)$

acoustic pressure amplitudes have resonance character. In turn, this character depends on the degree of difference in the values of the resonance frequencies of the external and internal shells.

In the case when the resonance frequency $f_{2}$ of the internal shell is less than the resonance frequency $f_{1}$ of the external one (Fig. 2), the pressure frequency dependence has principally one resonance region. This region is located near the resonance frequency of the external shell and is a single-humped curve. In this context the resonance frequency band does not exceed $45 \%$.

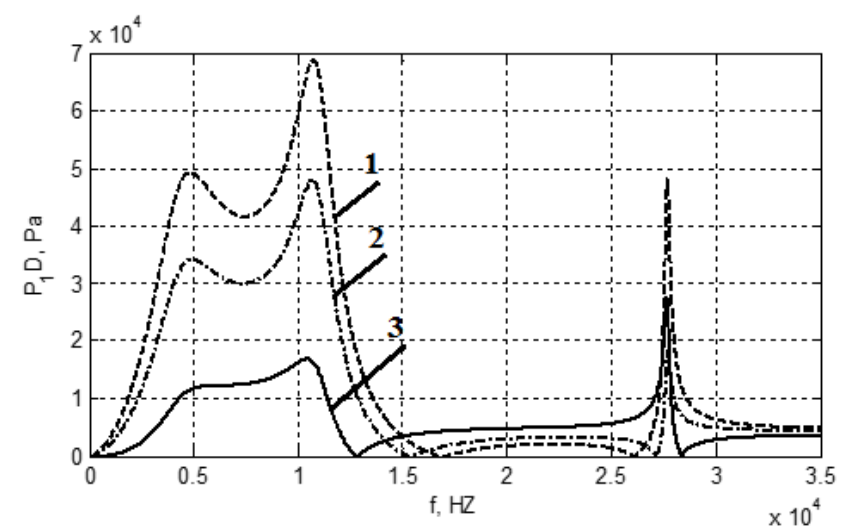

a

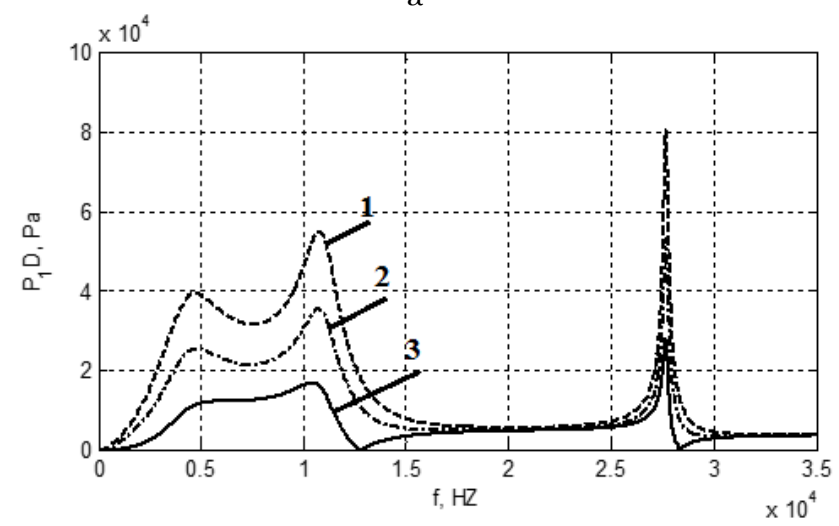

b

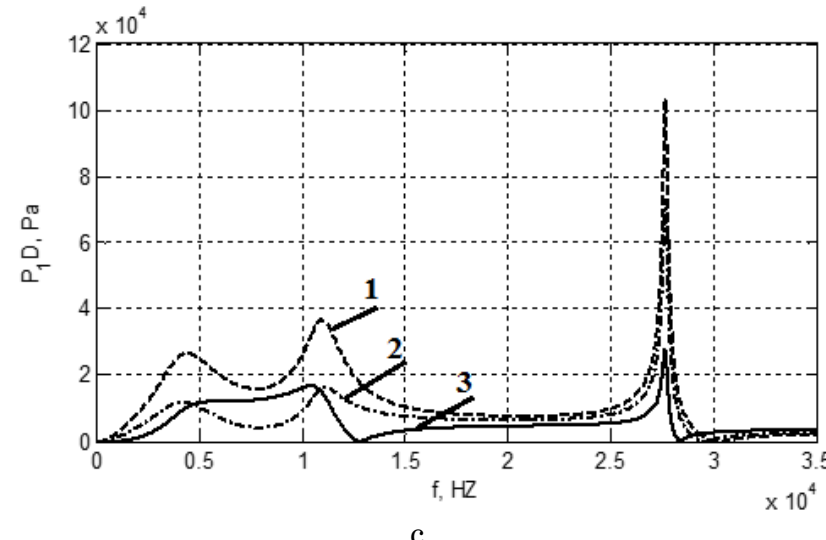

Fig. 3 - Frequency dependences of acoustic pressure amplitudes of the dynamically excited acoustoelectronic device at $f_{1}=3.5 \mathrm{kHz} ; f_{2}=3.64 \mathrm{kHz}$;

$\frac{\Psi_{02}}{\Psi_{01}}=1.0(1) ; 0.6(2) ; 0(3) ; \varphi=0(a) ; \frac{\pi}{2}(b) ; \pi(c)$

In case when the resonance frequencies of the internal and external shells are close (Fig. 3), the frequency dependence of the pressure varies significantly. Two resonance regions already appear in the frequency range in question. The first region begins near the resonance frequencies of the shells and is a twohumped curve with a dip between the humps expanding towards higher frequencies. The resonance frequency band increases to almost two octaves. In its form, the pressure frequency characteristic in this region is similar to that given in work [5]. The second resonance region is narrowband and is formed in the frequency 

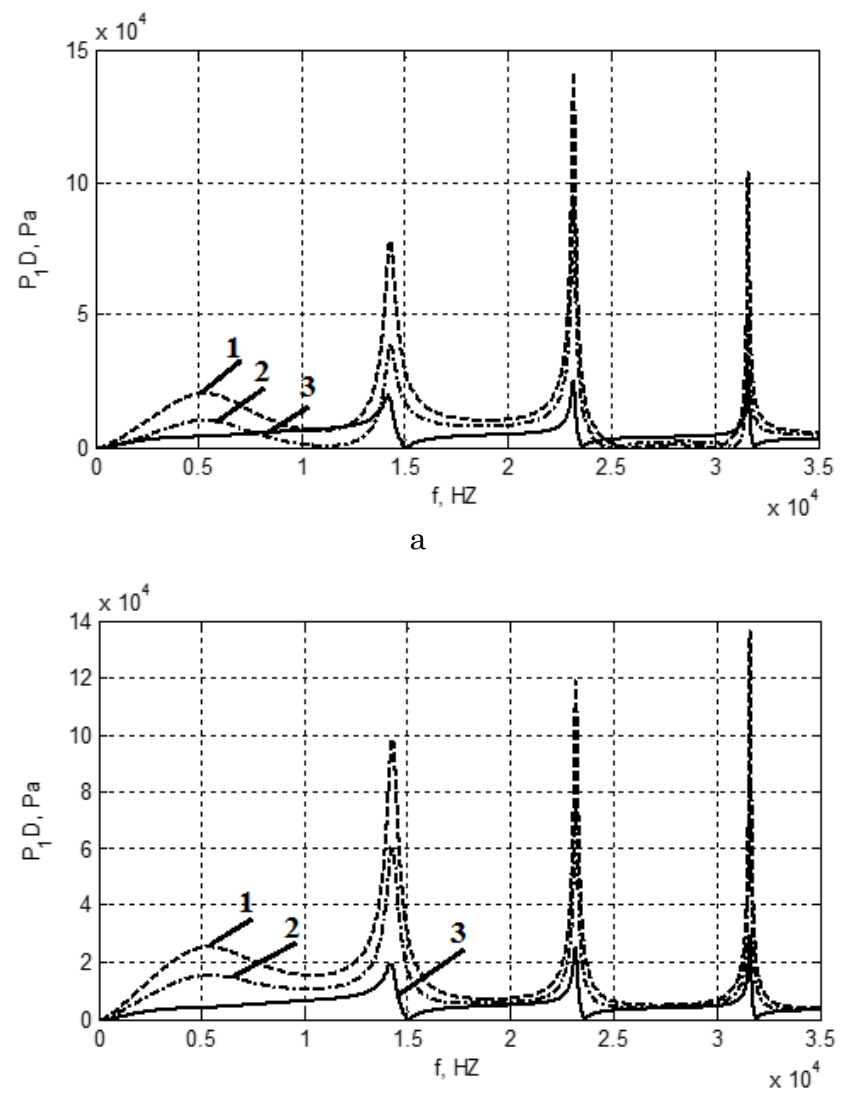

$\mathrm{b}$

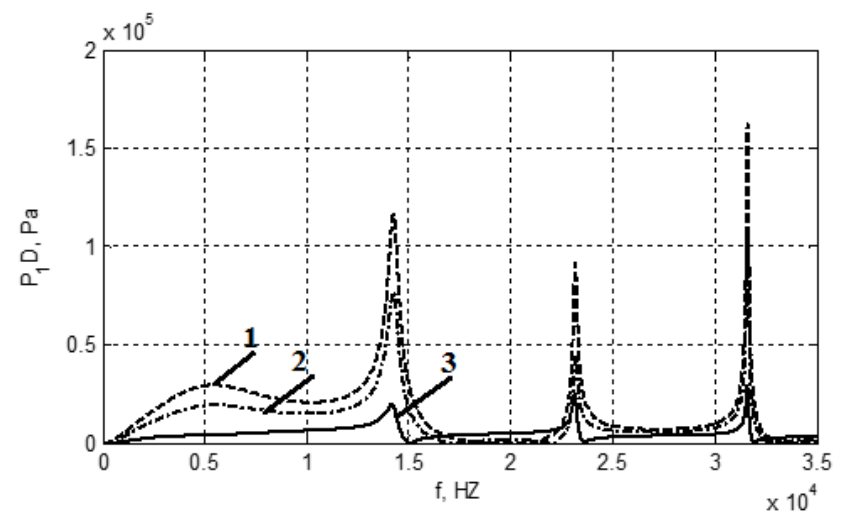

c

Fig. 4 - Frequency dependences of acoustic pressure amplitudes of the dynamically excited acoustoelectronic device at

$f_{1}=3.5 \mathrm{kHz} ; f_{2}=5.1 \mathrm{kHz} ; \frac{\Psi_{02}}{\Psi_{01}}=1.0$ (1); 0.6 (2); 0 (3) ;

$\varphi=0(a) ; \frac{\pi}{2}(b) ; \pi(c)$

region which is more than seven times larger than the intrinsic frequency $f_{1}$ of the external shell. Between these resonance regions, there is a significant dip in the frequency dependence.

In the case when the resonance frequency $f_{2}$ of the internal shell exceeds the intrinsic frequency $f_{1}$ of the external shell (Fig. 4), further significant changes in the pressure frequency characteristic occur. They consist in the emergence of new resonance regions in the frequency range under consideration. The first reso- nance region includes an intrinsic resonance frequency $f_{1}$ of the external shell. Its resonance frequency band reaches one octave, and maximum pressure levels are several times less than those in other resonance regions. Other resonance regions follow each other at the same frequency interval between their resonance peaks. The resonance frequency bands in all frequency regions decrease as the resonance frequencies of the regions increase.

Thus, the analysis of the graphs in Fig. 2-Fig. 4 allows us to pay attention to several features that are specific for the potentially possible dynamic properties of the considered acoustoelectronic devices during changing the piezoceramic shells intrinsic resonance frequencies forming them. First, if resonance frequencies $f_{2}$ of internal shells are smaller than resonance frequencies $f_{1}$ of external shells, one resonance region is formed around frequency $f_{1}$ in the pressure frequency dependence. Second, if resonance frequencies $f_{1}$ and $f_{2}$ are close, two resonance regions are formed. Moreover, the low-frequency region includes both $f_{1}$ and $f_{2}$, has a very wide resonance band and the largest pressure amplitudes. Third, if $f_{2}>f_{1}$, many resonance regions are formed. Their resonance frequency bands are different and decrease as the frequency increases. In this case, the low-frequency region includes frequencies $f_{1}$ and $f_{2}$, has a wide resonance band (up to 1.5-2.0 octaves) and the lowest pressure levels compared to other resonance regions.

Now let us analyze how the set of potentially possible dynamic properties of the acoustoelectronic device under consideration with two-frequency resonance excitation are changed under operational control by means of exciting the amplitudes and phases of electric voltages. The curve analysis in Fig. 2-Fig. 4 allows us to establish patterns common to all potentially achievable dynamic properties. First of all, the remarkable thing is that the resonance character of the device physical fields' frequency dependences is preserved for all versions of dynamic properties operational control. At the same time, with an increase in excitation voltages amplitudes ratio $\frac{\left|\Psi_{02}\right|}{\left|\Psi_{01}\right|}$ the level of acoustic radiation in resonance frequencies regions increases. The excess of the radiation level is maximal for $\left|\Psi_{01}\right|=\left|\Psi_{02}\right|$, different for devices with different $f_{2}$ and varies compared to that at $\Psi_{02}=0$ three to seven times in the studied frequency region.

The introduction of a phase shift $\varphi$ between excitation voltages of device piezoceramic shells significantly affects the fields frequency dependences character in resonance regions at all values of the internal shell resonance frequency $f_{2}$. The increase in the value of $\varphi$ is manifested, first, in a change in the shape of the frequency dependences of the radiation level and, second, in a decrease in this radiation level. At the same time, in the regions of dips between resonances in the frequency dependences of radiation levels between resonances, these levels slightly depend on both amplitudes 
of excitation voltages and phase shifts between them.

The established dynamic properties of the acoustoelectronic device with two-frequency resonance excitation have a clear physical justification. It is based on the connection of electric, mechanical and acoustic fields during energy conversion in piezoceramic media, the connection of the device external and internal shells acoustic fields during an acoustic field forming in the space between shells due to multiple exchange of acoustic waves among them and the connection of the energy conversion processes and its formation in the acoustic field $[2,3,5,11,12]$. The feature of the electromechanoacoustic energy conversion in the device under consideration is that all three fields of each piezoceramic shell have radial symmetry. Therefore, electric fields "pump" their energy into mechanical fields of piezoceramic shells only at their oscillations zero mode, and mechanical fields form acoustic fields which are uniform in all directions. Relative proximity of the resonance frequencies of shells determines the forms of the frequency dependences of the acoustic radiation level in the first resonance region.

Peculiarity of the mechanoacoustic part of energy conversion and its formation in the space between shells is elasticity of this space and its finite sizes in a secant plane (Fig. 1). It is known [2] that standing waves arise in such spaces under certain conditions when wave sizes $\frac{r_{12}-r_{21}}{\lambda}$ reach values close to or multiple of 0.25 . These waves lead to the formation of intrinsic resonances in the shell elastic spaces of this device. Naturally, these processes are determined by the amplitudes of the excited waves, the phase shift between them, the space between the shells size values and the elasticity of the filling media. Therefore, the mechanoacoustic conversion and formation of acoustic energy in the space between shells are the reasons for the appearance of high-frequency resonance regions in the acoustoelectronic device under consideration.

\section{REFERENCES}

1. Yu.A. Koryakin, S.A. Smirnov, G.V. Yakovlev, Ship hydroacoustic equipment: state and actual problems (SanktPeterburg: Nauka: 2004).

2. V.T. Grinchenko, I.V. Vovk, V.T. Matsypura, Acoustics Wave Problems (Kyiv: Begell House: 2018).

3. O. Leiko, N. Bogdanova, A. Derepa, O. Pozdniakova, 2020 IEEE 40th International Conference on Electronics and Nanotechnology (ELNANO), 694 (2020).

4. C. Sherman, J. Butler, Transducers and Arrays for Underwater Sound (New York: Springer: 2007).

5. N.V. Bogdanova, A.G. Leiko, S.A. Naida, A.I. Drozdenko, J. Nano-Electron. Phys. 11 No 6, 06011 (2019)

6. B.S. Aronov, J. Acoustic. Soc. Am. 117, 210 (2005).

\section{CONCLUSIONS}

The analysis of acoustoelectronic devices in the form of a coaxial system including two cylindrical piezoceramic shells with two-frequency resonance excitation dynamic properties makes it possible to distinguish two groups of properties in them - potentially possible and operatively controlled. The first of them are determined by these devices design characteristics such as electrophysical parameters of the shells piezoceramics compositions; diameters, thicknesses and resonance frequencies of shells; physical parameters of their filling media. The second group consists of dynamic properties, which are the result of the device operational control from the electric side.

It has been found that the potentially possible dynamic properties of the device under consideration are determined by differences in resonance frequencies of its external and internal piezoceramic shells. It should be noted that the physical fields' frequency dependences of the device have a resonance character. The number of resonance regions increases with the difference between the resonance frequencies of the shells. The largest resonance frequency band has a first resonance region including resonance frequencies of the shells. All subsequent resonance regions are narrowband. A physical analysis of the reasons for the formation of such patterns is presented.

It has been shown that operational control of dynamic properties in the device under consideration by means of its shells excitation voltages amplitudes and phases preserves all regularities obtained for potentially possible dynamic properties, but changes radiation fields' frequency dependences shape and levels differently in different frequency regions.

The established features of dynamic processes in acoustoelectronic devices with two-frequency resonance excitation make it possible to ensure the search for ways to design them in the most rational way from the point of view of providing given dynamic properties.

7. V.S. Didkovskyi, A.G. Leiko, O.I. Drozdenko, Konstruiuvannia elektroakustychnykh pryladiv $i$ system dlia multymediinykh akustychnykh tekhnolohii (Kharkiv: FPP Amelianchyk: 2013) [In Ukrainian].

8. O. Drozdenko, K. Drozdenko, O. Leiko, L. Perchevska, 2020 IEEE 40th International Conference on Electronics and Nanotechnology (ELNANO), 815 (2020).

9. O.V. Korzhik, Hydroacoustic devices based on multimode piezoceramic converters (Kyiv: 2011).

10. V. Didkovskiy, S. Naida, V. Zaets, Eastern-European Journal of Enterprise Technologies 1 No 5, 97 (2019).

11. A.V. Derepa, A.G. Leiko, O.N. Pozdniakova, J. Nano- Electron. Phys. 9 No 3, 03017 (2017)

12. V.T. Grinchenko, A.F. Ulitko, N.A. Shulga, Mekhanika svyazannykh poley $v$ elementakh konstruktsiy. t.5. Elektrouprugost (Kiyev: Naukova dumka: 1989). 


\title{
Можливості керування динамічними властивостями циліндричного п'езокерамічного акустоелектронного пристрою з двочастотним резонансним збудженням
}

\author{
О.Г. Лейко, Н.В. Богданова, О.В. Богданов, О.І. Дрозденко, К.С. Дрозденко
}

Національний технічний університет Украйни "Киӥвський політехнічний інститут ілені I. Сікорського», вул. Політехнічна, 16, 03056 Київ, Украӥна

Показано, що в динамічних властивостях акустоелектронних пристроїв у вигляді співвісної системи 3 двох циліндричних п'езокерамічних оболонок з електричним збудженням кожної з оболонок на своїй резонансній частоті, можливо виділити дві групи пов'язаних між собою властивостей: потенційно можливі і оперативно керовані. Перші визначаються характеристиками конструкцій цих пристроїв - електрофізичними параметрами п'єзокераміки оболонок; діаметрами, товщиною і резонансними частотами оболонок; фізичними параметрами середовищ їх заповнення. Другу групу утворюють оперативно керовані з електричного боку пристроїв ї динамічні властивості. Методом чисельного аналізу на прикладі акустичних полів встановлені закономірності поведінки потенційно можливих динамічних властивостей розглянутих пристроїв для варіантів їх побудови, коли резонансна частота внутрішньої оболонки менша, близька або більша за резонансну частоту зовнішньої оболонки, і кількісний вплив на них оперативних динамічних методів керування з електричного боку пристроїв. Дано фізичне трактування причин виникнення описаних динамічних властивостей.

Ключові слова: Акустоелектронний пристрій, Двочастотне резонансне збудження, Динамічні властивості, Потенційно можливі, Оперативно керовані. 